\title{
Crohn's Disease in a Southern European Country: Montreal Classification and Clinical Activity
}

\author{
Fernando Magro, MD, PhD ${ }^{1-3}$ Francisco Portela, MD, ${ }^{1,4}$ Paula Lago, MD, ${ }^{1,5}$ João Ramos de Deus, MD, ${ }^{1,6}$ \\ Ana Vieira, MD, ${ }^{1,7}$ Paula Peixe, MD, ${ }^{1,8}$ Isabelle Cremers, MD, ${ }^{1,9}$ José Cotter, MD, 1,10 Marília Cravo, MD, PhD ${ }^{1,11}$ \\ Lourdes Tavares, MD, 1,12 Jorge Reis, MD, ${ }^{1,13}$ Raquel Gonçalves, MD, ${ }^{1,14}$ Horácio Lopes, MD, ${ }^{1,15}$ \\ Paulo Caldeira, MD, ${ }^{1,16}$ Paula Ministro, MD, ${ }^{1,17}$ Laura Carvalho, MD, ${ }^{1,18}$ Luis Azevedo, MD, ${ }^{1,3,19}$ and \\ Altamiro da Costa-Pereira, MD, PhD, ${ }^{1,3,19}$ GEDII*
}

\begin{abstract}
Background: Given the heterogeneous nature of Crohn's disease (CD), our aim was to apply the Montreal Classification to a large cohort of Portuguese patients with $\mathrm{CD}$ in order to identify potential predictive regarding the need for medical and/or surgical treatment.
\end{abstract}

Methods: A cross-sectional study was used based on data from an on-line registry of patients with $\mathrm{CD}$.

Received for publication January 14, 2009; Accepted January 18, 2009.

From the ${ }^{1}$ Portuguese Group of Studies of Inflammatory Bowel Diseases, ${ }^{2}$ Hospital de São João; ${ }^{3}$ Faculty of Medicine, Oporto University, Portugal, ${ }^{4}$ Hospitais da Universidade de Coimbra, ${ }^{5}$ Hospital Geral de Santo António, ${ }^{6}$ Hospital Amadora Sintra, ${ }^{7}$ Hospital Garcia de Orta, ${ }^{8}$ Hospital Egas Moniz, ${ }^{9}$ Hospital de S. Bernardo Setubal, ${ }^{10}$ Centro Hospitalar do Alto Ave - Guimarães, ${ }^{11}$ Instituto Português Oncologia Francisco Gentil-Lisboa, ${ }^{12} \mathrm{Hospital}$ de Santa Maria-Lisboa, ${ }^{13}$ Hospital Pulido Valente-Lisboa, ${ }^{14}$ Hospital S MarcosBraga, ${ }^{15} \mathrm{Hospital}$ das Caldas da Raínha, ${ }^{16} \mathrm{Hospital}$ de Faro, ${ }^{17} \mathrm{Hospital}$ S.Teotónio-Viseu, ${ }^{18}$ Hospital de Vila Real, ${ }^{19}$ Department of Biostatistics and Medical Informatics - Faculty of Medicine, Oporto University, Portugal.

*GEDII: Amadeu Corte Real Nunes; Ana Isabel Valente; Ana Isabel Vieira; Antónia Duarte; António Marques; Antonio Queiroz; Bernardino Ribeiro; Carolina Duesca; Celeste Fátima Viveiros; Cidalina Caetano; Claudia Sequeira; David Horta; Edgar Gencsi; Estela Monteiro; Fernando Magro; Filipe Gomes Silva; Francisco Portela; Glória Marinho; Helder Cardoso; Helena Vasconcelos; Helena Sousa; Henrique Morna; Horácio Lopes; Isabel Bastos; Isabel Medeiros; Isabel Seves; Isadora Rosa; João Baranda; João Ramos de Deus; Jorge Amil Dias; J Godinho Lopes; João Freitas; J. Pinto de Matos; Jorge Reis; Jorge Vieira; Jose Cotter; José Estevens; J M Ribeiro; Laura Carvalho; Leopoldo Matos; Luís Correia; Luís Jasmins; Luis Lebre; Luísa Barros; Luísa Gloria; Lurdes Tavares; Marília Cravo; Margarida Marques; Marie Isabelle Cremers; Maria do Rosário Maldonado; Manuel Correia; Maria de Lurdes Gonçalves; Mário César; Miguel Areia; Manuela Ferreira; Mário Júlio Campos; Marta Salgado; Nuno Almeida; Paulo Andrade; Paula Lago; Paula Ministro; Paula Moura Santos; Paula Peixe; Paulo Caldeira; Paulo Freire; Pedro Martins; Raquel Gonçalves; Ricardo Ferreira; Ricardo Freire; Rui Loureiro; Rui Sousa; Rute Cerqueira; Salazar Sousa; Salomé Costa Lima; Sara Folgado Alberto; Silvia Leite; Sofia Mendes; Sónia Barroso; Sandra Lopes; Sónia Nobre; Tiago Bana e Costa; Vítor Fernandes. Supported by a Portuguese Schering-Plough grant.

Reprints: Fernando Magro, Institute of Pharmacology and Therapeutics, Faculdade de Medicina, 4200 Porto, Portugal (e-mail: fm@med.up.pt).

Copyright (C) 2009 Crohn's \& Colitis Foundation of America, Inc.

DOI 10.1002/ibd.20901

Published online 23 February 2009 in Wiley InterScience (www.interscience. wiley.com).
Results: Of the 1692 patients with 5 or more years of disease, 747 (44\%) were male and 945 (56\%) female. On multivariate analysis the A2 group was an independent risk factor of the need for steroids (odds ratio $[\mathrm{OR}] 1.6,95 \%$ confidence interval $[\mathrm{CI}] 1.1-2.3$ ) and the $\mathrm{A} 1$ and $\mathrm{A} 2$ groups for immunosuppressants (OR 2.2; CI 1.2-3.8; OR 1.4; CI 1.0-2.0, respectively). An $\mathrm{L} 3+\mathrm{L}_{4}$ and $\mathrm{L}_{4}$ location were risk factors for immunosuppression (OR 1.9; CI 1.5-2.4), whereas an L1 location was significantly associated with the need for abdominal surgery $(P<0.001)$. After 20 years of disease, less than $10 \%$ of patients persisted without steroids, immunosuppression, or surgery. The Montreal Classification allowed us to identify different groups of disease severity: A1 were more immunosuppressed without surgery, most of A2 patients were submitted to surgery, and $52 \%$ of $\mathrm{L} 1+\mathrm{L}_{4}$ patients were operated without immunosuppressants.

Conclusions: Stratifying patients according to the Montreal Classification may prove useful in identifying different phenotypes with different therapies and severity. Most of our patients have severe disease.

\section{(Inflamm Bowel Dis 2009;15:1343-1350)}

Key Words: Crohn's disease, Montreal Classification, Portugal, southern Europe, predictive factors, clinical activity

C rohn's disease $(\mathrm{CD})$ is a chronic inflammatory disease associated with significant morbidity due to a frequent need for intestinal resections and hospitalizations. Accurate classification of $\mathrm{CD}$ would be most helpful in this respect to allow an early assessment of disease prognosis, thereby identifying and selecting patients for the most appropriate therapy according to disease subtype. The Montreal ${ }^{1}$ revision of the Vienna Classification, to our knowledge, was never validated in a large population cohort.

Furthermore, geographic variations in $\mathrm{CD}$ incidence and prevalence have long been reported, with Scandinavian countries exhibiting a higher incidence, as well as a more aggressive behavior as compared to patients from southern Europe. ${ }^{2}$ However, this assumption might be difficult to substantiate because, so far, very few population-based studies from southern Europe have been published. Also, most studies reporting on the natural history of $\mathrm{CD}$ utilized referral 
centers, which may create a "referral center" bias, that is, patients referred to quaternary medical centers may have the most severe phenotypes, most likely to undergo surgery and multiple medications, and may well not be a representative sample.

The purpose of the present study was to apply the Montreal Classification in a large cohort of Portuguese patients with CD from several centers across the country in order to minimize "referral bias" and then search for predictive factors that would enable us to identify patients requiring steroid treatment, immunosuppression, and/or abdominal surgery. The Montreal Classification was used to allow a uniform and standardized classification of the cohort, thereby making possible for us to understand the clinical activity of this group of patients in a southern European country.

\section{PATIENTS AND METHODS}

\section{Patient Inclusion}

From September 2004 until December 2006, all medical doctors in Portugal (gastroenterologists, pediatricians, surgeons, and general practioners) were invited to include patients with IBD in a national database registry. Our national database was approved by national authorities and was implemented by the Portuguese group of studies for IBD (http:// www.gedi.med.up.pt/). It is a cross-sectional study that includes 77 Portuguese MDs coming from 33 medical centers, distributed all over Portugal, from north to south, including the islands of Madeira and Azores. Patient registration was carried out through a Web-based system with password and user name validated by a scientific committee. The patients came from quaternary and tertiary referral hospitals (48.6\%) and regional hospitals plus private practice $(50.7 \%)$. A small percentage $(0.5 \%)$ was included by pediatricians working in referral pediatric centers. These figures represent about $50 \%$ of the calculated number of Portuguese patients with IBD. All definitions of the material form were online and all participants had at least 3 meetings per year to discuss the inclusion criteria. All patients included in the present study had to fulfill the strict international diagnostic criteria for IBD. ${ }^{3}$ In addition, all patients were required to have at least 2 criteria from the Copenhagen Diagnostic Criteria of $C D .^{3}$

\section{Data Collection}

Information on date of onset of symptoms and diagnosis, type of clinical onset, extent of disease, familial occurrence of IBD, presence of extraintestinal manifestations, type of colonic involvement, presence of rectal involvement, type of anal lesion, previous history of abdominal abscesses and/or fistulas, clinical course, response to steroids, immunosuppression and/or biologic treatment, as well as previous abdominal or anal surgery was collected. Abdominal surgery was considered as such when patients submitted to surgery for intes- tinal resection, abscess drainage, strituroplasty, or another procedure such as appendectomy or acute abdomen without intestinal resection (i.e., diagnosis of $\mathrm{CD}$ without resection). The Montreal Classification ${ }^{1}$ was used. In this classification, L4 is a modifier that can be added to L1-L3 when concomitant upper gastrointestinal (GI) disease is present. Behavior was defined as B1 nonstricturing, nonpenetrating, B2 stricturing, $\mathrm{B} 3$ penetrating, and $\mathrm{p}$ is added to $\mathrm{B} 1-\mathrm{B} 3$ when concomitant perianal disease is present. Patients were defined as steroid-dependent if it was not possible to decrease the prednisolone dose below $10 \mathrm{mg} /$ day or if they required 2 or more steroid treatments $(1 \mathrm{mg} / \mathrm{kg})$ within a period of 6 months. Steroid resistance was defined as an incapability of inducing remission with steroids at a dose of $1 \mathrm{mg} / \mathrm{kg}$. Patients who have had treatment with azathioprine, 6-MP, cyclosporine, or methotrexate were included in the immunosuppression group.

\section{Disease Severity}

Patients were classified in 6 disease severity categories, a modification of the Silverstein et $\mathrm{al}^{4}$ classification. Score 1 was reserved for mild disease (without steroids, immunosuppressants, biologic treatment, or surgery at any given year of disease); score 2 for moderate disease (patients treated with corticosteroids requiring a dose of prednisolone above 10 $\mathrm{mg} /$ day or 2 or more steroid treatments within a period of 6 months); score 3 for severe disease (patients treated with immunosuppressants without biologic treatment or surgery); score 4 for severe refractory disease (patients treated with immunosuppressants and biologic treatment without surgery); score 5 for surgically treated disease (patients without use of immunosuppressants or biologic treatment); and finally, score 6 for severe refractory disease who came to need surgery and also immunosuppressants and biologic treatment.

\section{Statistics}

The Kolmogorov-Smirnov test was used to test for normality. When testing a hypothesis about continuous variables, parametric tests (Student's $t$-test and 1-factor analysis of variance, ANOVA) and nonparametric tests (Mann-Whitney and Kruskal-Wallis tests) were used as appropriate, taking into account normality assumptions and the number of groups compared. When testing a hypothesis about categorical variables a chi-square test and Fisher's exact test were used, as appropriate. In order to have a more thorough understanding of the factors associated with the use of steroid therapy, immunosuppression and abdominal surgery univariate and multivariate logistic regression modeling was used. In the multivariate logistic regression models the dependent variables were steroid therapy, immunosuppression, and abdominal surgery. Model goodness-of-fit was assessed using the Hosmer-Lemeshow statistic and discriminative power was evaluated by receiver-operator curve (ROC) curve analysis. The influence of outlier data values on model fit was 


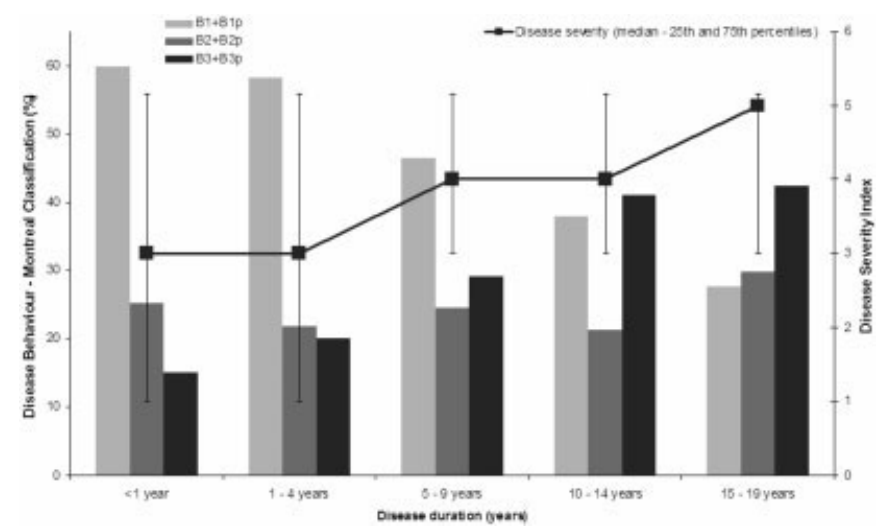

FIGURE 1. Behavior categories according to the Montreal Classification and clinical activity in different intervals of disease duration. Relative frequency (percentage) for each disease behavior category: Montreal Classification (left axis) and disease severity index (right axis) classified in 6 disease severity categories according to the modified Silverstein et $\mathrm{al}^{4}$ classification for each of the disease duration groups: $<1$ year $(n=274) ; 1-4$ years $(n=761) ; 5-9$ years $(n=673) ; 10-14$ years $(n=354)$; and $15-19$ years $(n=191)$.

estimated using leverage statistics, and collinearity was assessed by evaluation of coefficients correlation matrix. Because of the multiple hypothesis tests performed and presented in this study, the inflation of type I error is a risk. Whenever statistical hypothesis testing is used and in order to take into account a correction for the multiple comparisons presented, using the Bonferroni method, the significance level should be adequately corrected to $\alpha=0.002$ instead of the traditional $\alpha=0.05$ level. Statistical analysis was performed using the software Statistical Package for the Social Sciences v. 15.0 for Windows (SPSS, Chicago, IL).

\section{RESULTS}

\section{Analysis of Montreal Categories}

Of the 2854 patients with CD in our database, 1245 $(44 \%)$ were male and $1609(56 \%)$ female, with a mean age at diagnosis of $32 \pm 14$ years and a median time after diagnosis of 6 years (percentile 25, 2 and percentile 75, 11). Only patients with 5 or more years of disease were included in this analysis because it is a necessary timepoint before behavior might be classified. This approach seems to be imperative when results of different centers are compared. Behavior progression and clinical severity at different intervals of disease duration are shown in Figure 1. Sixty percent of patients in the first year of disease were categorized as B1; moreover, this percentage decreases with disease progression and only $28 \%$ of those with 15-19 years of disease had no stenosing or penetrating event (B1). By contrast, the B3 group increases in those with longer disease duration, achieving $42 \%$ in the longest affected group. Considering disease severity, we observed that during the first 4 years of disease the median severity was 3 (interquartile range 1-5), increasing to 4 (3-5) in those with 10-14 years of disease, and to 5 (3-5) in patients with 15-19 years of disease duration.

Table 1 shows characteristics of our study group according to age of diagnosis. Of the 1692 patients, 747 (44\%) were male and $945(56 \%)$ female. Mean age at diagnosis was $31 \pm 13$ years. Median time after diagnosis was 10 years (percentile 25, 7 and percentile 75,16 ). With regard to age at diagnosis, $8 \%$ were classified as A1 (below 16 years), $73 \%$ as A2 (below 40 years), and 19\% as A3 (above 40 years). Median time of follow-up after diagnosis was 10 years (percentile $25 \%, 7$; percentile $75 \%, 16$ ). A family history of IBD was present in $8 \%$ of the patients.

Table 2 shows classification of patients according to the Montreal Classification. Appropriate allocation of patients to different categories of disease location, age of onset, and behavior was possible in 1413 patients: 34\% were classified as L1 (ileal), $15 \%$ as L2 (colonic), $45 \%$ as L3 (ileocolonic), and $1 \%$ as L4 (upper GI disease). B1 (nonstricturing, nonpenetrating) phenotype was found in $38 \%$ of patients; B2 (structuring) in 26\% and B3 (penetrating) in 36\%. Colonic

TABLE 1. Baseline Population Characteristics

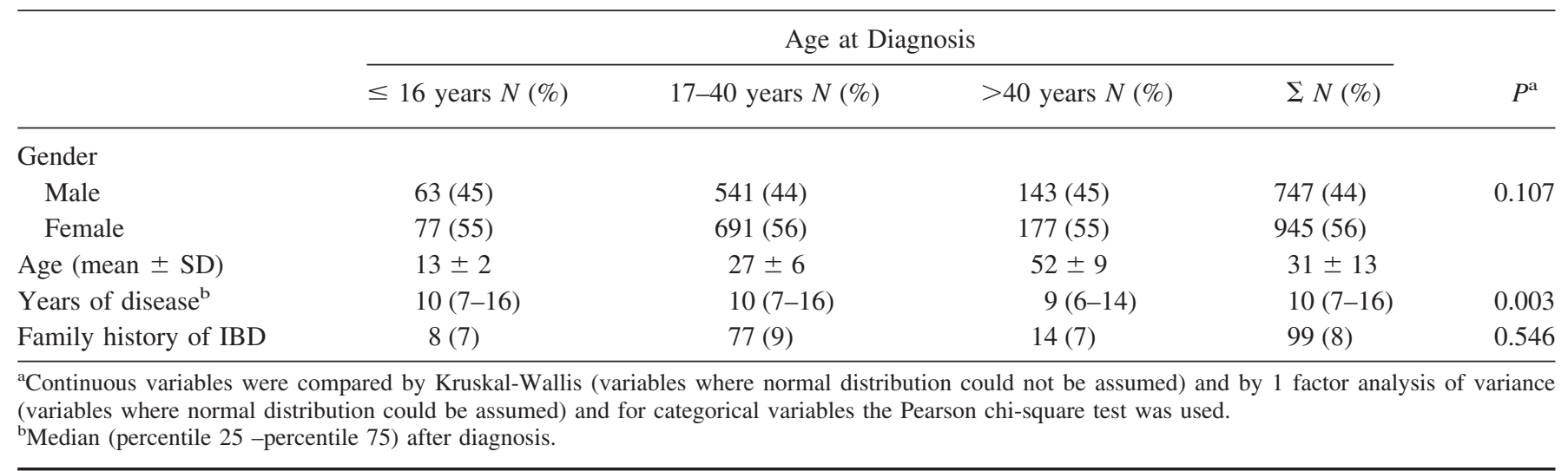


TABLE 2. Allocation of Patients to All 126 Subgroups of the Montreal Classification

\begin{tabular}{|c|c|c|c|c|c|c|c|c|c|c|c|c|c|c|c|c|c|c|c|}
\hline & \multicolumn{6}{|c|}{ A1 } & \multicolumn{6}{|c|}{$\mathrm{A} 2$} & \multicolumn{6}{|c|}{ A3 } & $\Sigma$ \\
\hline L2 & 0.8 & 0.1 & 0.2 & 0 & 0.1 & 0.3 & 6.9 & 0.5 & 1.6 & 0.6 & 0.1 & 0.8 & 1.8 & 0.4 & 0.6 & 0.4 & 0 & 0.1 & 15.1 \\
\hline L3 & 1.4 & 0.8 & 1.1 & 0 & 0.1 & 0.6 & 9.8 & 7.5 & 10.3 & 0.7 & 0.6 & 4.3 & 2.8 & 1.6 & 2.0 & 0.1 & 0.1 & 0.7 & 44.7 \\
\hline L4 & 0 & 0 & 0 & 0 & 0 & 0 & 0.3 & 0.5 & 0.2 & 0 & 0 & 0 & 0.1 & 0.1 & 0 & 0 & 0 & 0 & 1.2 \\
\hline $\mathrm{L}_{4}$ & 0 & 0.1 & 0.1 & 0 & 0 & 0 & 0.4 & 0.1 & 0.5 & 0 & 0 & 0.1 & 0.1 & 0.1 & 0.1 & 0 & 0 & 0 & 1.5 \\
\hline $\mathrm{L}_{4}$ & 0 & 0 & 0 & 0 & 0 & 0 & 0.1 & 0.1 & 0 & 0 & 0 & 0 & 0 & 0 & 0.1 & 0 & 0 & 0 & 0.4 \\
\hline$\Sigma$ & 3.3 & 1.5 & 1.9 & 0 & 0.5 & 1 & 24.7 & 18.3 & 20 & 1.6 & 1.3 & 6.9 & 7.6 & 4.7 & 4.8 & 0.6 & 0.2 & 1.2 & 100 \\
\hline
\end{tabular}

Percentage of the total population $(n=1413)$ is shown.

involvement was total in $23 \%$ patients, proximal in $30 \%$, segmental in $32 \%$, and left colonic involvement in $15 \%$.

\section{Analysis of Location, Behavior, and Treatment According to Age of Onset of CD}

A significant association between the age at diagnosis and disease location was found, with the youngest population (A1) exhibiting predominantly L3 involvement, whereas the oldest patients (A3) had mainly an L2 location $(P<0.001)$. The A1 group of patients were more often steroid-dependent (36\%, $P=0.030)$ and were more often taking immunosuppressants $(62 \%, P<0.001)$ and biologic agents $(22 \%, P$ $<0.001$ ) (Table 3). By contrast, we observed that the A3 group ( $>40$ years at diagnosis) had a lower incidence of abdominal fistulas and both steroids and immunosuppressants were less often prescribed (Table 3).

\section{Severity}

The population was stratified by different years of disease duration. In all, 1704 patients had at least 5 years of disease, 919 patients 10 or more years, 497 at least 15 years, 26220 or more years of disease, and 136 had disease for at least 25 years. It was observed that only a minority of patients $(<10 \%)$ did not receive steroids, immunosuppressants, or were submitted to abdominal surgery. Twenty-seven percent of patients became steroid-dependent and $49 \%$ of them required immunosuppressants, with or without biologic treatment. Of note, the majority of patients required surgery at some point - at 5 years of diagnosis the first surgery rate was $22 \%$ rising to $38.5 \%, 52 \%, 67 \%$, and $66 \%$, at $5-9,10-14$, $15-19,20-24$, and more than 25 years after diagnosis, respectively. Table 4 shows the severity of disease in 6 different categories according to the Silverstein et $\mathrm{al}^{4}$ modified classification. Thus, considering age of onset it was observed that $20 \%$ patients in the A3 group were assessed as mild disease and only $7 \%$ were stratified in the highest severe
TABLE 3. Contingency Table for Age at Diagnosis, Type of Penetrating Events, Medical and Surgical Treatment

\begin{tabular}{|c|c|c|c|c|}
\hline & $\begin{array}{c}\mathrm{A} 1 \\
N(\%)\end{array}$ & $\begin{array}{c}\mathrm{A} 2 \\
N(\%)\end{array}$ & $\begin{array}{c}\mathrm{A} 3 \\
N(\%)\end{array}$ & $P^{\mathrm{a}}$ \\
\hline \multicolumn{5}{|l|}{ Location } \\
\hline $\mathrm{L} 1+\mathrm{L1}_{4}$ & $66(32)$ & $733(36)$ & $226(38)$ & \multirow{4}{*}{0.001} \\
\hline $\mathrm{L} 2+\mathrm{L}_{4}$ & $31(15)$ & $408(20)$ & $161(27)$ & \\
\hline $\mathrm{L} 3+\mathrm{L}_{4}$ & $107(52)$ & $847(42)$ & $208(35)$ & \\
\hline $\mathrm{L} 4$ & $2(1)$ & $22(1)$ & $7(1)$ & \\
\hline \multicolumn{5}{|l|}{ Upper GI involvement } \\
\hline & $7(5)$ & $72(6)$ & $22(7)$ & 0.693 \\
\hline \multicolumn{5}{|l|}{ Behavior } \\
\hline $\mathrm{B} 1+\mathrm{B} 1 \mathrm{p}$ & $86(48)$ & $788(45)$ & $273(52)$ & \multirow{3}{*}{0.047} \\
\hline $\mathrm{B} 2+\mathrm{B} 2 \mathrm{p}$ & $45(25)$ & $444(25)$ & $123(23)$ & \\
\hline $\mathrm{B} 3+\mathrm{B} 3 \mathrm{p}$ & $49(27)$ & $527(30)$ & $128(24)$ & \\
\hline EIM & $61(44)$ & $429(35)$ & $110(35)$ & 0.07 \\
\hline \multicolumn{5}{|c|}{ Abdominal penetrating events } \\
\hline Abscesses & 24 (17) & $176(15)$ & $38(12)$ & 0.298 \\
\hline Fistulas & $21(15)$ & $231(19)$ & $39(12)$ & 0.018 \\
\hline \multicolumn{5}{|c|}{ Anal penetrating events } \\
\hline Fissures & $17(12)$ & $93(8)$ & $15(5)$ & 0.018 \\
\hline Abscesses & $22(16)$ & $165(13)$ & $36(11)$ & 0.391 \\
\hline Fistulas & $34(23)$ & $271(22)$ & $62(19)$ & 0.442 \\
\hline $\begin{array}{l}\text { Patients treated } \\
\text { with steroids }\end{array}$ & $119(88)$ & $965(82)$ & $214(72)$ & 0.001 \\
\hline Steroid dependent & $42(36)$ & $266(28)$ & $47(22)$ & 0.030 \\
\hline Steroid resistant & $9(8)$ & $58(6)$ & $9(4)$ & 0.434 \\
\hline Immunosuppression & $85(62)$ & $621(51)$ & $121(38)$ & 0.001 \\
\hline Biologic treatment & $30(22)$ & $222(18)$ & $41(13)$ & 0.020 \\
\hline Abdominal surgery & $64(46)$ & $609(50)$ & $141(44)$ & 0.215 \\
\hline Anal surgery & $23(17)$ & $231(19)$ & $44(14)$ & 0.098 \\
\hline
\end{tabular}

EIM, extraintestinal manifestations.

aPearson chi-square test. 
TABLE 4. Contingency for Age at Diagnosis, Location, and Behavior According to Treatment, Classified in 6 Disease Severity Categories (Modification of Silverstein et al $^{4}$ Classification) Silverstein Score

\begin{tabular}{|c|c|c|c|c|c|c|c|}
\hline & \multicolumn{7}{|c|}{ Silverstein Score } \\
\hline A1 & $7(8)$ & $4(5)$ & $27(32)$ & $14(17)$ & $18(21)$ & $14(17)$ & \\
\hline A2 & 89 (12) & $13(2)$ & $183(24)$ & $96(13)$ & $259(35)$ & $108(14)$ & 0.001 \\
\hline A3 & $41(20)$ & $5(3)$ & 38 (19) & $24(12)$ & $80(40)$ & $14(7)$ & \\
\hline $\mathrm{L} 1+\mathrm{L1}_{4}$ & $66(18)$ & $5(1)$ & $55(15)$ & $26(7)$ & $194(52)$ & $31(8)$ & \\
\hline $\mathrm{L} 2+\mathrm{L} 2{ }_{4}$ & $32(15)$ & $7(3)$ & $70(32)$ & $59(27)$ & $26(12)$ & $25(11)$ & 0.001 \\
\hline $\mathrm{L} 3+\mathrm{L}_{4}$ & $36(9)$ & $8(2)$ & $120(28)$ & 49 (12) & $135(32)$ & $76(18)$ & \\
\hline \multicolumn{8}{|l|}{ Behavior } \\
\hline $\mathrm{B} 1+\mathrm{B} 1 \mathrm{p}$ & $100(30)$ & $11(3)$ & $13(37)$ & $48(15)$ & $38(11)$ & $14(4)$ & \\
\hline
\end{tabular}

score. In contrast, the majority of A1 patients were treated with immunosuppressants without need of surgery and most of the A2 patients submitted to surgery (49\%). When the patients were categorized by location it was possible to identify different groups of activity. It is very interesting that $52 \%$ of $\mathrm{L} 1+\mathrm{L} 1_{4}$ were operated on without immunosuppressants or biologic treatment. Regarding behavior classification, in the B1 group $30 \%$ of patients were classified as having mild disease, and in contrast $77 \%$ of penetrating patients required surgery.

\section{Univariate and Multivariate Analysis of Factors Associated with Steroid Therapy, Immunosuppression, and Abdominal Surgery}

Table 5 shows the variables that were associated with the use of steroids, immunosuppressants, and/or surgery on uni- and multivariate analysis. Of interest, early age of disease onset did not represent a risk factor for steroid dependency or abdominal surgery; however, the presence of extraintestinal manifestations (EIMs) was associated with increased risk of steroid dependence. With respect to immunosuppressants, we observed that besides the A1 and A2 groups, other risk factors were $\mathrm{L} 3+\mathrm{L} 3_{4}$ and $\mathrm{L} 4$ location, $\mathrm{B} 2+\mathrm{B} 2 \mathrm{p}$ and $\mathrm{B} 3+\mathrm{B} 3 \mathrm{p}$ groups, and the presence of perianal disease, EIM, as well as the previous use of steroids, namely, steroid dependency (odds ratio [OR] 10.3; $95 \%$ confidence interval [CI] 7.1-15.0) or steroid resistance (OR 6.7; CI 2.8-16.0). With regard to surgery, multivariate analysis showed that risk factors were $\mathrm{L} 1+\mathrm{L}_{4}$ location, $\mathrm{B} 2+\mathrm{B} 2 \mathrm{p}$ and $\mathrm{B} 3+\mathrm{B} 3 \mathrm{p}$ behaviors, the presence of abdominal abscesses or fistulas, and steroid resistance.

\section{DISCUSSION}

Based on mesalamine consumption in the year 2005 and considering a daily drug intake-defined dose (DDD) of 2 $\mathrm{g} /$ day, the prevalence of IBD in Portugal was estimated to be 118 per 100,000 inhabitants, that is, 12,508 estimated Portuguese patients with IBD. The same study estimated a prevalence of CD of 60 per 100,000 inhabitants. ${ }^{5}$ Based on these numbers, we believe that half of the $\mathrm{CD}$ patients in Portugal were included in this study, which may be considered a representative sample.

To our knowledge this is the first study assessing the Montreal Classification in a large cohort of patients with CD. Most of the patients came from hospitals from north to south Portugal, as well as the islands of Madeira and Azores, covering all types of hospital care (primary to quaternary) in an attempt to overcome a "referral-bias" which might have existed if we only included patients from major referral centers. Most of the investigators involved in the study were senior gastroenterologists, and patients seen in private practice were also included. The Montreal Classification individualized, for the first time, a group for early onset of disease, younger than 16 years old, allowing the investigation and categorization of a pediatric group. According to previous work, this group seems to be characterized by specific sero- 


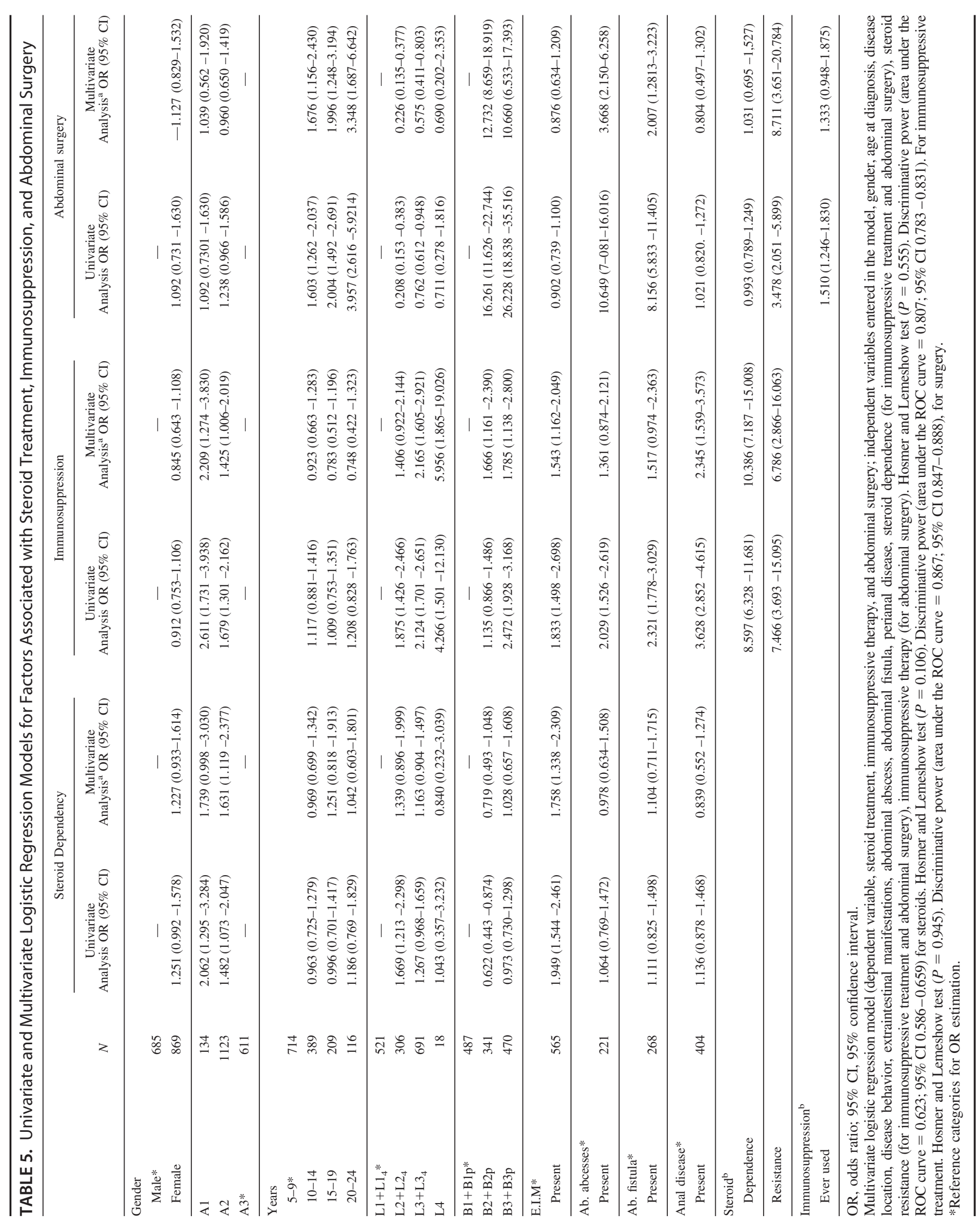


types and genotypes. ${ }^{1}$ In our population, A1 patients appear to be a different CD group. They were more often steroiddependent and immunosuppressed and they had more EIMs. This is in agreement with previous studies which report a more severe phenotype with steroid resistance and a greater need for immunosuppression. ${ }^{6}$ These findings further emphasize the need for early steroid-sparing medications in pediatric IBD. As opposed to what could be expected, we observed a low frequency of patients with a family history (7\%) of CD in the pediatric group, thereby suggesting that genetic factors are not as important in the early onset phenotype and suggesting that pediatric IBD is still evolving, and points to environmental factors contributing to its pathogenesis.

Patients with disease diagnosed after 40 years of age, in agreement with a previous study, ${ }^{7}$ were less frequently steroid-dependent, and consequently, immunosuppression and biologic therapy was less often prescribed. However, in our study group we did not find a tendency for a decreased rate of abdominal surgery, as reported before. ${ }^{8}$ With respect to disease location, the most important difficulty with the Vienna Classification arose with the inability of allowing upper GI involvement to coexist with distal disease. The Working Party of the 1998 Vienna World Congress of Gastroenterology, ${ }^{9}$ reported that $7 \%$ of patients were reported as $\mathrm{L} 4$, but in the presents series only $1 \%$ of our patients had exclusive location in the upper digestive tract. This is similar to a previous study from Freeman, ${ }^{10}$ who reported a low exclusive involvement of the upper digestive tract $(0.8 \%)$. Thus, the majority of patients who have upper GI tract involvement also have disease in other locations. In the present series, $3.3 \%$ of upper GI tract involvement was associated with ileal location $\left(\mathrm{L1}_{4}\right), 1.5 \%$ was associated with colonic disease $\left(\mathrm{L} 2_{4}\right)$, and $0.4 \%$ with ileocolonic disease $\left(\mathrm{L}_{4}\right)$. Overall, $5.2 \%$ of patients included in this study had upper GI tract involvement, although these numbers might change with the wider utilization of wireless capsule endoscopy.

Also, in the Vienna Classification perianal fistulizing disease was included in the penetrating behavior group, but the Working Party felt that perianal disease requires separate subclassification. ${ }^{1}$ In our cohort, $38 \%$ of patients had nonstricturing and nonpenetrating disease, while $26 \%$ were classified as stricturing and $36 \%$ as penetrating. As $4 \%$ of patients had perianal disease without any more abdominal penetrating events, in the present series we may admit that $4 \%$ of patients would be erroneously classified as penetrating disease according to the Vienna Classification.

CD location changes only minimally over time, as opposed to the disease behavior changing from pure inflammatory to stricturing or fistulizing disease, with almost $90 \%$ of patients progressing to complicated behavior after 20 years of disease. ${ }^{11,12}$ All these arguments favor the hypothesis that if we become accustomed to categorizing $\mathrm{CD}$ according to the Montreal Classification, in terms of location and age of onset, we may very well be able to predict which is the most probable outcome in the coming years, namely, need for steroids, immunosuppressants, and/or surgery. In this work to put out changes in location and behavior in the first years of disease, we only included patients with more than 5 years of disease. We observed that, in agreement with previous studies, ${ }^{13}$ ileal involvement was associated with the need for surgical interventions, as opposed to ileocolonic and upper digestive tract involvement, which were associated with immunosuppression. If we consider the severity index used herein, the Silverstein et $\mathrm{al}^{4}$ modified categorization, which basically reflects the step-up policy that most physicians still use when treating $\mathrm{CD}$, in ascending order sulfasalazine, 5-aminosalicylate, corticosteroids, immunosuppressants, and surgery, we found that disease phenotype, location, and age of disease onset were associated with different disease severity categories.

Finally, we would like to emphasize that in the present series, $78 \%$ of our patients had been on steroids, at least once, $49 \%$ had taken immunosuppressants at some point of their disease, and at least $48 \%$ submitted to surgery. Less than $10 \%$ of CD patients persisted without steroids, immunosuppressants, or abdominal surgery. These numbers are quite similar to previous series published from North America or from Denmark, ${ }^{14-19}$ and do not support the study by Wolters et al, ${ }^{2}$ where the authors concluded that southern CD had a milder course as compared to patients from northern Europe. They reported a phenotypic north-to-south gradient in CD, illustrated by higher surgery risks in some northern European centers, whereas patients from southern Europe were more likely to pass from severe disease to a milder state, and from there back to the no-medication state. However, it is important to recall that in the Wolters et al study ${ }^{2}$ there were only 13 Portuguese patients included. In a recent study from only one hospital in Portugal (quaternary medical center of IBD in the north), only $10 \%$ of patients maintained a long-term remission free of steroids after their initial presentation. ${ }^{20}$ Thus, according to the present results, we believe that rates of aggressive medical therapy and the need for surgical interventions are very similar to the ones observed and reported in northern European countries.

In conclusion, we were able to clearly demonstrate that there are prognostic differences in the subgroups of patients allocated by the Montreal Classification. Our study shows that stratifying $\mathrm{CD}$ patients with respect to disease location as well as age of disease onset may prove useful in predicting the subsequent course in terms of steroids requirement, immunosuppression, and/or surgical interventions. Furthermore, we also want to emphasize that this is probably the largest study coming from a country in southern Europe. In contrast to what had been reported previously, but similar to the series from northern Europe, only a minority of patients will have mild disease. 


\section{REFERENCES}

1. Satsangi J, Silverberg MS, Vermeire S, et al. The Montreal classification of inflammatory bowel disease: controversies, consensus, and implications. Gut. 2006;55:749-753.

2. Wolters FL, Joling C, Russel MG, et al. Treatment inferred disease severity in Crohn's disease: evidence for a European gradient of disease course. Scand J Gastroenterol. 2007;42:333-344.

3. Munkholm P. Crohn's disease-occurrence, course and prognosis. An epidemiologic cohort-study. Dan Med Bull. 1997;44:287-302.

4. Silverstein MD, Loftus EV, Sandborn WJ, et al. Clinical course and costs of care for Crohn's disease: Markov model analysis of a population-based cohort. Gastroenterology. 1999;117:49-57.

5. Magro F, Portela F, Lago P, et al. A pharmaco-epidemiological approach to estimate IBD prevalence and incidence in Portugal. J Crohn's Colitis. 2008;2:35.

6. Jacobstein DA, Mamula P, Markowitz JE, et al. Predictors of immunomodulator use as early therapy in pediatric Crohn's disease. $J$ Clin Gastroenterol. 2006;40:145-148.

7. Heresbach D, Alexandre JL, Bretagne JF, et al. Crohn's disease in the over-60 age group: a population based study. Eur J Gastroenterol Hepatol. 2004;16:657-664.

8. Tremaine WJ, Timmons LJ, Loftus EV Jr, et al. Age at onset of inflammatory bowel disease and the risk of surgery for non-neoplastic bowel disease. Aliment Pharmacol Ther. 2007;25:1435-1441.

9. Gasche C, Scholmerich J, Brynskov J, et al. A simple classification of Crohn's disease: report of the Working Party for the World Congresses of Gastroenterology, Vienna 1998. Inflamm Bowel Dis. 2000;6:8-15.

10. Freeman HJ. Application of the Vienna Classification for Crohn's disease to a single clinician database of 877 patients. Can J Gastroenterol. 2001;15:89-93.
11. Cosnes J, Cattan S, Blain A, et al. Long-term evolution of disease behavior of Crohn's disease. Inflamm Bowel Dis. 2002;8:244-250.

12. Louis E, Collard A, Oger AF, et al. Behaviour of Crohn's disease according to the Vienna classification: changing pattern over the course of the disease. Gut. 2001;49:777-782.

13. Henriksen M, Jahnsen J, Lygren I, et al. Clinical course in Crohn's disease: results of a five-year population-based follow-up study (the IBSEN study). Scand J Gastroenterol. 2007;42:602-610.

14. Loftus EV Jr, Schoenfeld P, Sandborn WJ. The epidemiology and natural history of Crohn's disease in population-based patient cohorts from North America: a systematic review. Aliment Pharmacol Ther. 2002;16:51-60.

15. Agrez MV, Valente RM, Pierce W, et al. Surgical history of Crohn's disease in a well-defined population. Mayo Clin Proc. 1982;57:747-752.

16. Munkholm P, Langholz E, Davidsen M, et al. Frequency of glucocorticoid resistance and dependency in Crohn's disease. Gut. 1994;35:360362.

17. Munkholm P, Langholz E, Davidsen M, et al. Intestinal cancer risk and mortality in patients with Crohn's disease. Gastroenterology. 1993;105: $1716-1723$

18. Binder V, Hendriksen C, Kreiner S. Prognosis in Crohn's diseasebased on results from a regional patient group from the county of Copenhagen. Gut. 1985;26:146-150.

19. Jess T, Riis L, Vind I, et al. Changes in clinical characteristics, course, and prognosis of inflammatory bowel disease during the last 5 decades: a population-based study from Copenhagen, Denmark. Inflamm Bowel Dis. 2007;13:481-489.

20. Veloso FT, Ferreira JT, Barros L, et al. Clinical outcome of Crohn's disease: analysis according to the Vienna classification and clinical activity. Inflamm Bowel Dis. 2001;7:306-313. 